\title{
AADL を使った安全な車椅子ロボットの正式モデル
}

\author{
An AADL model of the control architecture for a safe robot wheelchair \\ BIGGS Geoffrey（産総研）＼cjkstart藤原 清司（産総研）穴田啓樹（キャッツ株式会社）
}

Geoffrey BIGGS, National Institute of Advanced Industrial Science and Technology

Kiyoshi FUJIWARA, National Institute of Advanced Industrial Science and Technology Keiju ANADA, CATS Co., Ltd.

\begin{abstract}
As the complexity of robots deployed in the real world increases, the use of formal specifications in the development of safety-critical robot systems is becoming increasingly important. A formal specification gives confidence in the correctness, completeness, and accuracy of a system design. In this paper, we present a model of a redundant control architecture for a mobile robot. The model is specified using the Architecture Analysis and Design Language (AADL). This formal language allows the model to be analysed to prove system properties such as sufficient processor capacity and control latency. We present the results of a model completeness analysis, a processor capacity analysis, and a latency analysis.
\end{abstract}

\section{1. はじめに}

ロボット等の様な cyber-physical system （サーバー物理 システム）の設計・開発には、センサーからの情報を運動に 変更する制御アーキテクチャの設計が大事な活躍である。セ ンサー、マイコン、制御ソフトウェア、アクチュエータ、及 びそれぞれを接続するバスの設計が必要である。しかし、設 計だけは高信頼ロボットの場合に不十分である。制御アーキ テクチャの設計が正確だとの証明も必須である。

飛行機、鉄道等の様な各分野には、formal specification（形 式設計）の使うことが尋常になって来た。システムの正確さ、 開発時間及び高信頼への利点は確率である。それでも、ロボッ 卜分野にはまだほとんど使われていない。

近年、制御アーキテクチャの正確さ等を形式的に証明する用 のツールが開発され、複雑な制御アーキテクチャでも正確に設 計することが可能になって来た。そのツールの一つは AADL (Architecture Analysis and Design Language) である。本 文では、我々は高信頼・安全ロボット車椅子の冗長化制御アー キテクチャの AADL モデルを発表する。AADL の正式な設 計及びモデルに対しての自動分析によって制御アーキテクチャ の正確さを証明する。

\section{AADL とは}

AADL (Architecture Analysis and Design Language) と いうのは、組込みシステムの電気品・ソフトウェアアーキテク チャ用の形式的なモデル言語である $[1]$ 。宣言型な言語で、振 る舞いより構造を主張する。組込みし捨てものソフトウェア 構造、実行ハードウェア構造、及びセンサーやアクチュエー 夕等のデバイスの指定だけではなくて、ソフトウェアを実行 ハードウェアへのマッピングも指定可能である。

AADL には、形式的なシマンテックとシンタックスがある。 これによって、モデルの正確さの確認も、自動分析によって 実行時間等の様なシステムプロパティの確認も可能である。 本分の複数の章 4 . で複数の分析とその結果を発表する。

AADL でモデルの記述と分析を行うために複数のツールが 存在する。本文では、OSATE (Open Source AADL Tool Environment）を使う [2]。このツールはAADL のコンパイ ラ、シマンテック・シンタックス確認ツール、モデル正確さ確 認ツールが含まれている。その上で、自動分析ツールとして コネクション確認分析、プロセススケジュール分析やフロー レーティンシ分析等複数のツールが含まれている。

3. 安全車椅子ロボットの制御アーキテクチャモデル

[3] で記述された高信頼・安全車椅子ロボットの制御アーキ テクチャの AADL で記述したモデルを紹介する。車椅子ロ ボット及びそれの制御アーキテクチャは、ISO 61508 の SIL3 に対して設計・開発された $[4]$ 。

モデルで記述されていることは、マイコンもモータが冗長
化された起動ロボットの速度制御アーキテクチャである。速 度制御の一部として、障害物がある場合ロボットが減速・停 止用に制御する。このアーキテクチャは、センサー・制御コ ンピュータ・ドライブ・電源等で故障があってもロボットは 必ず止まることを保証する。

アーキテクチャモデルは複数のサブシステムとデバイスに 分割されている。これらを構成すると全体的の制御ア一キテ クチャモデルができた（図 1)。モデルの複雑さを制限する為 に、センサーとアクチュエータはブラックボクスデバイスと して扱われている。すべてのサブシステム・デバイスはバス で接続されている。

冗長かされたマイコンユニット（Control Unit）はサブシ ステムのインスタンスとしてモデル化されている。両方の構 造は同じである（図 2)。マイコンユニットの中には実行する 制御ソフトウェア（ctrl_procプロセス）が含まれ、そのソ フトウェアを実行する為のマイコンとメモリが入っている。 トップレベルシステムにはこのマイコンユニットのインスタ ンスは二つがある。

ctrl_proc プロセスの中で実行されるソフトウェア (thread) は図 3 に示す。速度コマンド入力と障害物のデー タを合わせて安全なモータコマンドに変更することの中で特 定なロールを持つ五つのスレッドに分けている。

モータを含むドライブユニットもマイコンユニットと同様 に二つのサブシステムインスタンスでとしてモデル化されて いる。そして、マイコンユニットと同様に二つも中の構造が 同じである（図 4)。ドライブユニットには、AC モータ・電 磁ブレーキ・冗長的に回転速度を計るレゾルバとエンコーダ が含まれている。

冗長化された制御アーキテクチャは実装された。実行ハー ドウェア（マイコン）はルネサス株式会社の SH72AW マイ コンであり、冗長のために二つが使われている。SH72AW は $160 \mathrm{MHz}$ のクロックで RAM は $96 \mathrm{~KB}$ である。モータは 二台の AC モータである。モータ・車輪は一台づつである。 センサーは 北陽電気株式会社の UAM-01LP-T301 レーザセ ンサ（障害物への距離用）及びストリップスイッチ（障害物 との接触用）である。すべてのセンサは安全性の検討で使わ れている。

\section{4. モデルの死式的な分析}

AADL の形式的なシマンテックによって、モデルに対して 様々な自動分析を行うことが可能である。分析可能なことは ツール及びモデルに含まれている情報だけで制限されている。 本章では、安全制御アーキテクチャモデルの分析を発表する。

\section{1 モデルの正確さと完全さ}

モデルの完成さと正確さはモデルに対して行う分析の正確 さに大きな影響がある。モデルにエラーがあったら、分析の 結果は不正確になりか称ない。これによって、アーキテクチャ 
mobile_robot_ctrl_arch_Instance

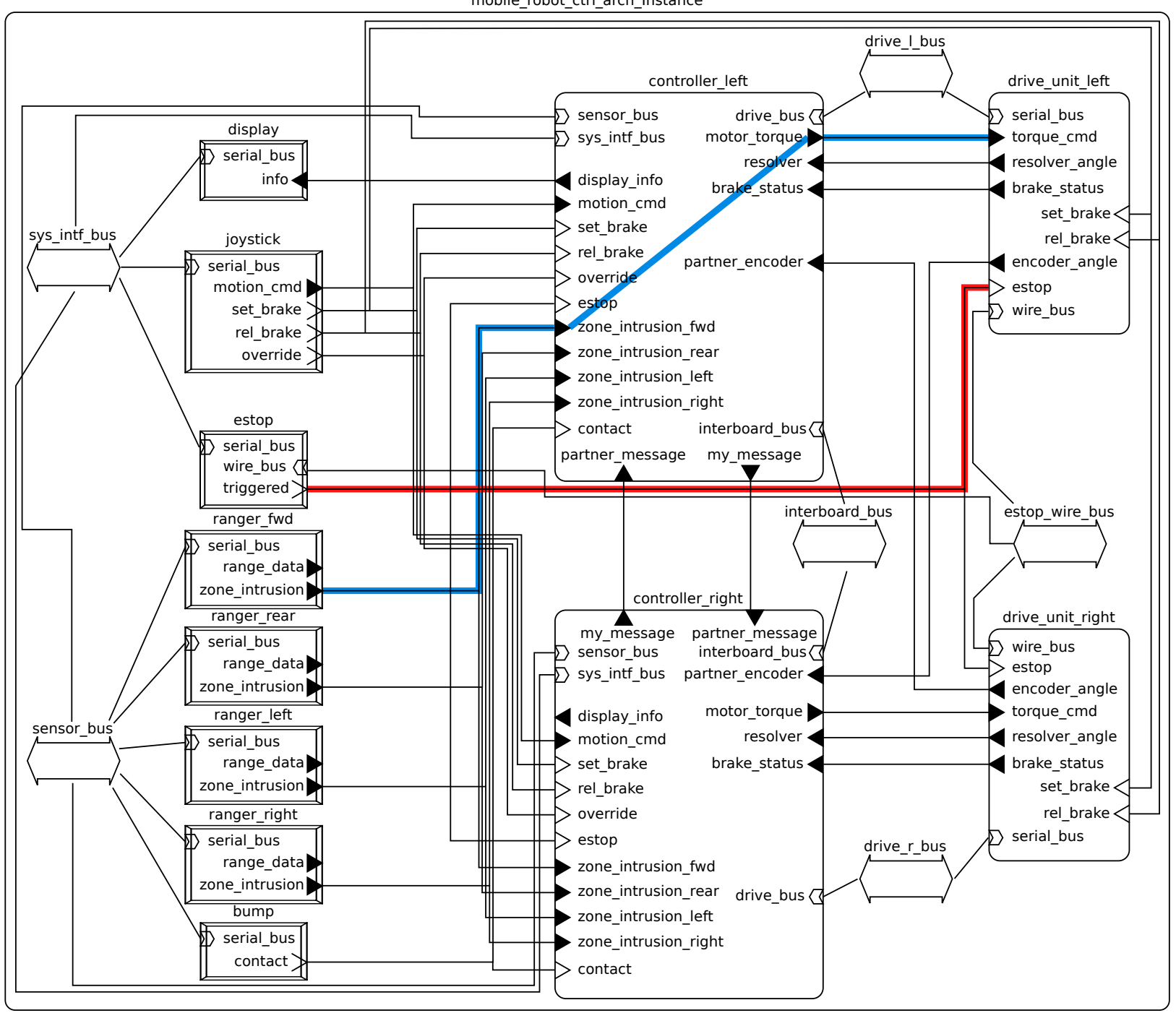

Fig.1: The top level of the safety architecture AADL model

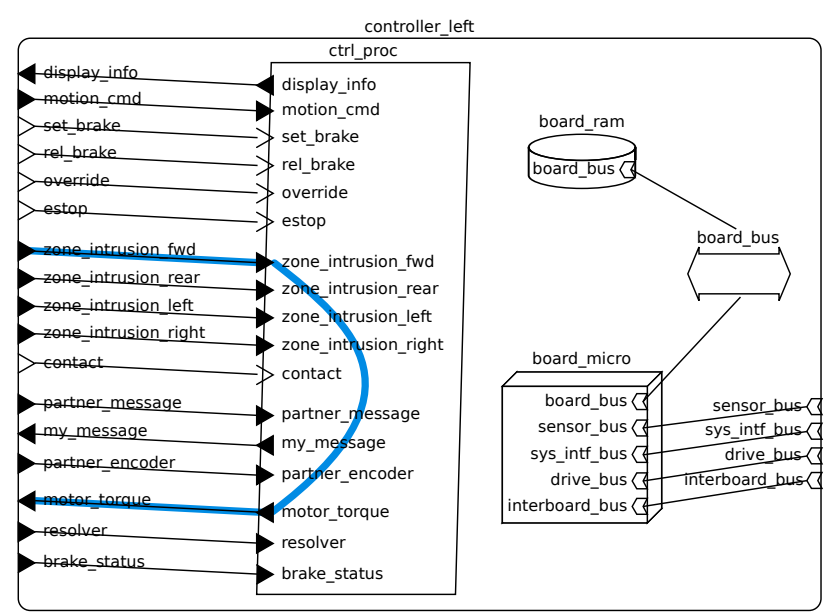

Fig.2: The control unit sub-system

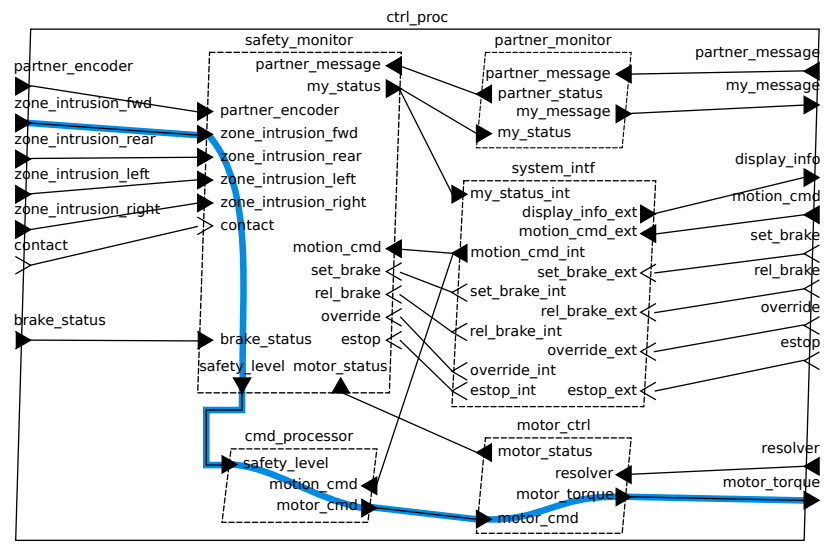

Fig.3: The software (processes and threads) that executes on a single controller 
$\checkmark$ (4) Warnings (2 items)

(4) No connection declaration from feature zone_intrusion_fwd of component ctrl_proc to subcomponents. Connection instance ends at ctrl_proc

(4) No connection declaration from feature zone_intrusion_fwd of component ctrl_proc to subcomponents. Connection instance ends at ctrl_proc

Fig.5: The results of performing a connection analysis on the safety architecture model, showing a warning when a required connection is missing

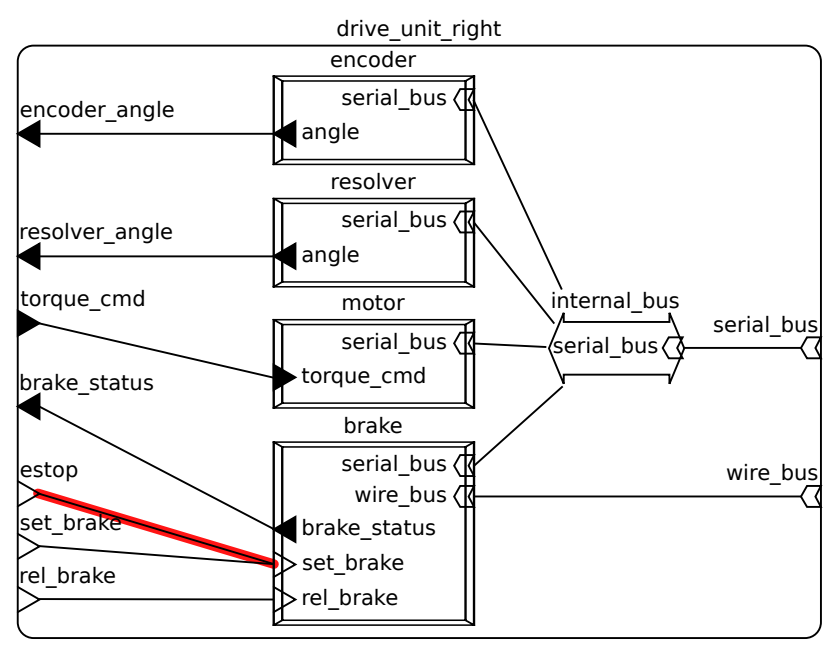

Fig.4: The drive unit sub-system

の設計・実装にフォルトが導入しかねる。特に、AADL では 未完成なモデルでもコンパイル・分析を行うことは可能なの で、モデルの未完成な所は分析結果に影響があるかどうか開 発者が分かるべきである。

例えば、OSATE で AADL モデルに「connection consistency analysis」を行うことが可能である。この分析の結果に よって、以下のことが分かる。

1.コネクションが必須であるポートのすべてはコネクショ ンがある。

2. コネクションづつに、両側のポートはデータ型等の互換 性がある。

その上に、connection consistency analysis の結果でモデ ルの完成さの判断が可能である。例えば、コンポーネントの 外向きのポートからとのどれかのサブコンポーネントへの接 続が必要です。ない場合は、コンポーネントの設計はまだ未 完成であると判断できます。この場合では、OSATE は図 5 の用な注意を表示する。

\section{2 ソフトウェアの実行スケジュール}

ソフトウェアスレッドのスケジュール（実効順番）は組込 みシステムの振る舞いに影響がある。正しい振る舞いをする ために実効期限が大事なリアルタイムな組込みシステムにス ケジュールは特に大事である。AADL モデルにスレッドの 実効時間・実効期限とプロセサの実効能力（クロック頻度と MIPS）が含まれていると、自動的にスレッドのプロセサへ の配布とそのプロセサづつの実効スケジュール作成及びスケ ジュール分析が可能になる。他の分析は、スレッドがバス軽 油でセンサ等のハードウェアやデータが入っているメモリへ アクセスプロセサにマッピングされたことの確認ができる。

スレッドのスケジュール自動作成を行うために、以下の情 報がスレッドごとに必要である。

1. 実効期限及びピリオド

2. 実効期間

3. 必要な MIPS (MIPS budget)

ビンパッキングアルゴリズムを使って、必要な接続等を考
虑しながらスレッドをプロセサへのマッピングの作成ができ るツールはOSATE に含まれている。二つのプロセサが含ま 机る安全制御アーキテクチャモデルでこのツールを使うと、 左側の制御スレッドと右側の制御スレッドが正しく分けら机、 左側プロセスと右側プロセサにマッピングされた。自動マッ ピングの結果で、右側のモータを制御するスレッドが右側用 のプロセサに配布され、左側のモータを制御するスレッドが 左側用のプロセサに配布される。

スケジュールによってプロセサロードの計算ができるツー ルも OSATEに含ま机いる。このツールによって、あるプ ロセサはマッピングされたスレッドを実効する容量が持つか どうか及びそのスレッドは実効期限に間に合うかどうかの確 認が可能である。安全制御アーキテクチャモデルのプロセサ ロード計算結果が、両方のプロセサは $50 \%$ ロードになると のことです。本文では、スレッドづつの必要な MIPS の正確 な值がなかったので、実効期間とプロセサの MIPS によって 見積もった。（制御ソフトウェアが $10 \mathrm{~ms}$ で実効し、スレッ ドづつに $1 \mathrm{~ms}$ の実効期限が付いていることに基づいて計算 した。）この用な見積りはソフトウェア実装の前にアーキテク チャが設計されている場合によく作られていることである。

\section{3 レティンシ}

組込みシステムのレティンシ（反応時間）は入力と出力の 時間差によっで決められている。AADLには、データ処理の 流机を「flow」としてモデル化するとレティンシーの計算が 可能になる。Flow というのはシステムのコンポーネントを 通るデータ・制御の道であり、モデルの開発者が指定するこ とである。一般的には、センサやインターフェース等の入力 デバイス（「 「 source」）から、その入力を処理するプロセサ． ソフトウェア軽油（「path」）で、アクチュエータ等の出力す るデバイス (「sink」) までの流机がモデル化されている。

安全制御アーキテクチャモデルの緊急停止スイッチからの 信号の流れが図 1 及び図 4 で赤い線として示す。スイッチを モデルするデバイスで初め、直接接続されたワイアバス軽油 でドライブユニットに流れる。この用な直接な流机の低いレ ティンシが表 1 で示す。

障害物情報が前向きのレンジセンサで出されたことからド ライブユニットへのモータ制御コマンドが届くことまでの流 れが図 1、図 2 及び国 3 で青い線として示す。センサのレティ ンシや制御ソフトウェアの処理が含まれ、緊急停止スイッチ からの流机より複雑である。よって、この流机のレティンシ は緊急停止スイッチのレティンシより高い。最低の場合のレ ティンシは $90 \mathrm{~ms}$ である（表 2）。それでも、レティンシは 十分早いである。時速 $8 \mathrm{~km}$ の場合は、障害物の検出・処理・ モータ制御を行う間に車椅子ロボットがただの 0.25 メート ルを動く。

\section{5. おわりに}

本文では、AADL という形式的にアーキテクチャ設計用の モデル言語を使い、高信頼・安全車椅子ロボットの圥長化さ れた制御アーキテクチャをモデルかした。AADL の簡単な宣 言型なセマンティクスとシンタックスのおかげで、モデルの 作成は簡単であった。特に役に立ったことは、AADL のモデ ルはコンパイル可能であり、コンパイルすることによってモ デルのエラ一等が自動的に見つけられる。SysML の用なコン パイルできない言語と比べると、正確なモデルは作りやすい との意見を持つ。 
Table 1: The latency of the emergency stop signal, assuming a maximum brake response time of $50 \mathrm{~ms}$

\begin{tabular}{llll}
\hline Model element & Name & Flow spec & Total \\
\hline device & estop & $0.001 \mathrm{us}$ & $0.001 \mathrm{us}$ \\
connection & $\begin{array}{l}\text { estop.triggered }-> \\
\text { drive_unit_left.brake.set_brake }\end{array}$ & $0.0 \mathrm{~ms}$ & $0.001 \mathrm{us}$ \\
system & $\begin{array}{l} \\
\text { drive_unit_left:estop_flow_sink }\end{array}$ & $50.0 \mathrm{~ms}$ & $50.000001 \mathrm{~ms}$ \\
\hline
\end{tabular}

Table 2: The latency of responding to an obstacle

\begin{tabular}{|c|c|c|c|c|c|}
\hline Model element & Name & Deadline & Sampling delay & Flow spec & Total \\
\hline device & ranger_fwd & $0.0 \mathrm{~ms}$ & $0.0 \mathrm{~ms}$ & $30.0 \mathrm{~ms}$ & $30.0 \mathrm{~ms}$ \\
\hline connection & $\begin{array}{l}\text { ranger_fwd.zone_intrusion } \rightarrow \\
\text { controller_left.ctrl_proc. } \\
\text { safety_monitor.zone_intrusion_fwd }\end{array}$ & $0.0 \mathrm{~ms}$ & $0.0 \mathrm{~ms}$ & 0.0 us & $30.0 \mathrm{~ms}$ \\
\hline thread & $\begin{array}{l}\text { controller_left.ctrl_proc. } \\
\text { safety_monitor:zi_flow_path }\end{array}$ & $10.0 \mathrm{~ms}$ & $10.0 \mathrm{~ms}$ & 0.5 us & $40.0 \mathrm{~ms}$ \\
\hline connection & $\begin{array}{l}\text { safety_monitor.safety_level -> } \\
\text { cmd_processor.safety_level }\end{array}$ & $0.0 \mathrm{~ms}$ & $0.0 \mathrm{~ms}$ & $0.0 \mathrm{~ms}$ & $50.0 \mathrm{~ms}$ \\
\hline thread & $\begin{array}{l}\text { controller_left.ctrl_proc. } \\
\text { cmd_processor:zi_flow_path }\end{array}$ & $10.0 \mathrm{~ms}$ & $10.0 \mathrm{~ms}$ & 0.5 us & $60.0 \mathrm{~ms}$ \\
\hline connection & $\begin{array}{l}\text { cmd_processor.motor_cmd } \rightarrow \\
\text { motor_ctrl.motor_cmd }\end{array}$ & $0.0 \mathrm{~ms}$ & $0.0 \mathrm{~ms}$ & $0.0 \mathrm{~ms}$ & $70.0 \mathrm{~ms}$ \\
\hline thread & $\begin{array}{l}\text { controller_left.ctrl_proc. } \\
\text { motor_ctrl:zi_flow_path }\end{array}$ & $10.0 \mathrm{~ms}$ & $10.0 \mathrm{~ms}$ & 0.5 us & $80.0 \mathrm{~ms}$ \\
\hline connection & $\begin{array}{l}\text { controller_left.ctrl_proc. } \\
\text { motor_ctrl.motor_torque } \rightarrow \\
\text { drive_unit_left.motor.torque_cmd }\end{array}$ & $0.0 \mathrm{~ms}$ & $0.0 \mathrm{~ms}$ & $0.0 \mathrm{~ms}$ & $90.0 \mathrm{~ms}$ \\
\hline
\end{tabular}

作成したモデルを使い、複数の自動分析を行った。これら の結果で、モデルとそのモデルが指定する設計が正確である と証明できた。さらな分析で、ソフトウェアスレッドのプロ セサへのマッピングに問題がなく、予想のリアルタイムの奏 効期限が果たせることも証明できた。そして、レティンシ分 析の結果が、ロボットの反応時間を最大速度と合わせたら問 題は予想されていないとのエビデンスになる。これらの自動 分析の結果が、設計したアーキテクチャがアプリケーション・ 要求等にふさわしいとの証明になる。

\section{参献}

[1] SAE International. "Architecture Analysis \& Design Language (AADL) (AS5506B)", 2012.
[2] Peter, H. F. and Gluch, D. P.: Model-Based Engineering with AADL, chap. 15. Addison-Wesley, Westford, Massachusetts, USA (2012)

[3] 藤原 清司, 中坊 嘉宏, 穴田 啓樹, Geoffrey Biggs, 水口 大知, “ディペンダブルロボット車両のハードウェア試作”, 日本機械学会 ロボティクス・メカトロニクス講演会 2012 講演論文集, pp. 1P1-S02, 2012.

[4] IEC 61508-2 Functional safety of electrical/electronic/programmable electronic safety-related systems Part 2: Requirements for electrical/electronic/programmable electronic safety-related systems, 2010. 